\title{
SUSTITUCIÓN DEL FISCAL EN EL SISTEMA ACUSATORIO
}

\author{
SUBSTITUTION OF THE PROSECUTOR IN THE ACCUSATORY SYSTEM
}

\author{
Roberto Ulises Zavaleta-de-los-Santos \\ 1. Escuela Judicial del Estado de Tabasco, México. zavaletaroberto@hotmail.com \\ * Autor de correspondencia: Roberto Ulises Zavaleta-de-los-Santos, correo electrónico: zavaletaroberto@hotmail.com
}

\section{RESUMEN}

La impunidad y corrupción son flagelos siempre presentes en la impartición de justicia. La falta de capacidad técnica del fiscal en las audiencias preliminares y de juicio, genera en muchos casos impunidad y en otros casos es generada por la corrupción. El presente artículo aborda este tema, a través de un método de casos que tiene como actividad central el análisis de dicha problemática presente en las audiencias. La finalidad es darle sentido a la norma constitucional federal cuando establece en su fracción I, apartado A, del artículo 20, “el proceso penal tendrá por objeto el esclarecimiento de los hechos, proteger al inocente, procurar que el culpable no quede impune”. El análisis surge desde la práctica profesional, la hipótesis consiste en sostener la necesidad de justificar la sustitución del fiscal en el sistema penal acusatorio en México a través de los principios del propio sistema. La figura del fiscal como órgano técnico debe ser abordada, para lo cual es necesario exponer mecanismos, que permitan al juez esa sustitución entre tanto se establece en la norma de manera explícita.

Palabras claves: corrupción; impunidad; sustitución del fiscal; sistema acusatorio.

Cómo citar:

Zavaleta-de-los-Santos, Roberto Ulises. (2021). Sustitución del fiscal en el sistema acusatorio. Revista de Investigaciones Universidad del Quindio, 33(S2), 99-107. https://doi.org/10.33975/riuq.vol33nS2.618 


\begin{abstract}
Impunity and corruption are always present scourges in the administration of justice. The lack of technical capacity of the prosecutor in the preliminary and trial hearings generates impunity in many cases and in other cases it is generated by corruption. This article addresses this issue through a case method whose central activity is the analysis of said problems present in the hearings. The purpose is to give meaning to the federal constitutional norm when it establishes in its section I, section A, of article 20 , "the criminal process will have as its object the clarification of the facts, protect the innocent, and ensure that the guilty do not go unpunished." The analysis arises from professional practice; the hypothesis consists in sustaining the need to justify the substitution of the prosecutor in the accusatory criminal system in Mexico through the principles of the system itself. The figure of the prosecutor as a technical body must be addressed, for which it is necessary to expose mechanisms that allow the judge this substitution in the meantime it is explicitly established in the norm.
\end{abstract}

Keywords: corruption; impunity; substitution of the prosecutor; accusatory system.

\title{
INTRODUCCIÓN
}

Con la reforma de junio del 2008, el legislador, realizó un cambio en el sistema de justicia penal en México, de un sistema mixto a uno acusatorio adversarial, teniendo cambios favorables en la manera de impartir justicia. El sistema acusatorio para adaptarlo a nuestra realidad es necesario, realizar ciertos cambios que se tildan necesarios para ir haciéndolo cada vez más perfectible, y que tiene como finalidad de no aumentar el catálogo de delitos de prisión preventiva oficiosa, o el aumento de la pena de prisión en los tipos penales, como política criminal para combatir el delito.

Este cambio, se puede dar desde una óptica legislativa, es decir modificar la figura unipersonal del fiscal desde el Código Nacional de Procedimientos Penales, en el sentido de establecer la sustitución del fiscal por su notoria deficiencia. Tal y como acontece con la defensa, el cual puede ser sustituido por falta de una defensa técnica, o que dicha sustitución, se dé por parte del juez de control o enjuiciamiento utilizando mecanismos de interpretación de principio del sistema acusatorio.

De ahí, que sea motivo de este artículo el análisis de la sustitución del fiscal por su notoria incapacidad técnica. Comprendiendo su estudio desde la propia función del fiscal, de los principios del sistema acusatorio, como la tutela judicial efectiva, defensa adecuada, los derechos de la víctima, entre otros.

Lo anterior, tendría diversos beneficios al Estado de Derecho, ya que abatiría la impunidad y la corrupción por parte de la fiscalía, dar las razones de ello, desde la práctica profesional, se torna complejo, aun mas siendo el contrapeso de la fiscalía, pero quien no desea, que en igualdad de armas sea la defensa oída y vencida en juicio.

\section{METODOLOGÍA}

Este documento pretende dar al lector un acercamiento del contexto respecto a las capacidades técnicas del fiscal en las audiencias preliminares y de juicio. En ese sentido, se basó en un enfoque cualitativo con alcance descriptivo e interpretativo desarrollado en el método documental, estudio de caso y exegético. 


\section{RESULTADOS}

\section{Sistema de Justicia Penal Acusatorio en México}

El 18 de junio de 2008, fue publicado en el Diario Oficial de la Federación, el decreto por el que se reforman los artículos 16, 17, 18, 19, 20, 21 y 22; las fracciones XXI y XXIII del artículo 73; la fracción VII del artículo 115 y la fracción XIII del apartado B del artículo 123, todos de la Constitución Política de los Estados Unidos Mexicanos.

La reforma constitucional en materia penal representó un cambio de paradigma para todos los actores que conforman un Estado Democrático de Derecho. En México, el sistema de justicia Penal Acusatorio fue implementado en el año 2016, el cual tiene su fundamento principalmente en el artículo 20 de la Constitución Política de los Estados Unidos Mexicanos. Este sistema tiene como finalidad la solución de conflictos interpersonales de una manera más pronta, eficiente, justa, humana, transparente y respetuoso de los derechos humanos. Esto, a través de sus principios de publicidad, contradicción, concentración, continuidad e inmediación.

El sistema procesal acusatorio dio paso a un medio más dinámico y efectivo como es la oralidad. Andrés Baytelman y Mauricio Duce (2004) refieren que la oralidad constituye el único mecanismo idóneo para asegurar la inmediatez y la publicidad en el proceso. En la medida en que las pruebas y argumentos de las partes, no se presenten en forma oral y directa frente a los jueces que van a decidir el asunto, se corre el riesgo de la delegación de funciones y que el proceso se transforme en un intercambio de papeles entre las partes y el tribunal, al cual ni el acusado ni el público tendrían acceso.

Con motivo de la oralidad, las partes se deberán abstener de leer documentos completos o apuntes de sus actuaciones que demuestren falta de argumentación y desconocimiento del asunto. Esta formar de desarrollar las audiencias impide al juez de control o enjuiciamiento tener acceso a los registros de investigación. Situación, que se presenta durante el desarrollo de todo el proceso, tanto en las audiencias preliminares como en la audiencia de juicio, al señalar que esta será oral en todo momento. (CNPP, art. 396).

Registros de investigación, que no se podrá incorporar o invocar como medios de prueba ni dar lectura durante el debate, a los registros y demás documentos que den cuenta de actuaciones realizadas por policía o el Ministerio Publico en la investigación, con excepción de los supuestos expresamente previstos en el Código. (art. 385CNPP). El juez de control o enjuiciamiento, al no tener acceso a esos registros de investigación, en muchos casos desconoce si las partes del proceso se conducen con lealtad y probidad procesal. Lo anterior, genera un conflicto, cuando la actuación del fiscal genera que el culpable no sea condenado.

En algunos casos, no generalizados, es necesario que el juez de control o enjuiciamiento sustituya al fiscal, ante su manifiesta y sistemática incapacidad técnica. Esta sustitución, debe ser analizada a través de los principios de los sistema penal acusatorio.

\section{Función del Fiscal}

Es necesario señalar cuál es la función del fiscal en el sistema acusatorio en México. En ese sentido, al fiscal en el proceso penal le ha sido encomendada una función importante como salvaguarda del 
Estado de Derecho. En la recomendación del Consejo de Europa sobre la función del ministerio público en el sistema de justicia penal dicha tarea ha sido descrita de la siguiente manera: "lo fiscales son autoridades públicas que, en nombre de la sociedad y del interés público, garantizan la aplicación de la ley cuando el incumplimiento de la ley acarrea una sanción penal, teniendo en cuenta tanto los derechos del individuo, así como la eficacia necesaria del sistema de justicia penal" (Consejo de Europa, 2000).

La función del fiscal se encuentra establecida en la Constitución Política de los Estados Unidos Mexicanos (1917), y en el Código Nacional de Procedimientos Penales, como un órgano autónomo e independiente, el cual actúa en la base de la pirámide funcional en contraposición de la defensa. Su presencia en el proceso penal es como un órgano del Estado de persecución y acusación y por otra como parte del proceso penal. Por lo tanto, tiene la dirección de la investigación de los hechos constitutivos del delito (Fernández, 2005). Sus funciones son entonces, conducir la investigación, coordinar a la policía y a los servicios periciales durante la investigación, resolver sobre el ejercicio de la acción penal, acreditar la existencia del delito y la responsabilidad de quien lo cometió o participo en su comisión.

Cabe señalar que la función del fiscal ya no es sólo oficial, sino también es permitido la acción penal por particulares al conferirle esa propia facultad no solamente al Ministerio Público, sino además a la víctima u ofendido (por sí o a través de su asesor jurídico), pero ello no demerita la importancia de la participación del fiscal.

La participación del fiscal como generador de la actividad jurisdiccional, inicial con el ejercicio de la acción penal, siendo el control de detención o citación para formular imputación la forma de iniciar la investigación; también, en aquella etapa intermedia con la presentación de la acusación y en la etapa de juicio oral.

Durante la investigación, el fiscal dirige las funciones de policía, orientando, reorientando, coordinando, ordenando, controlando y evaluando la actuación de sus investigadores (Vasconcelos, 2014); busca y asegura, a través de la policía, los elementos probatorios; solicita y asiste a la realización de audiencias preliminares, como son la de legalización de captura, la imputación, la solicitud de vinculación a proceso, imposición, modificación de medida de medidas cautelares, plazo y prorroga de la investigación complementaria; interpone recursos y medios de impugnación para proteger los interese del Estado o de la parte ofendida, vela por la protección de víctimas y testigos; solicita medidas de protección para la víctima, el restablecimiento del derecho y la reparación integral; determina la forma conclusiva de la investigación, abstención de investigar, archivo provisional, no ejercicio de la acción penal, aplica el criterio de oportunidad, busca y negocia los acuerdos reparatorio, también la suspensión condicional del proceso, solicita el sobreseimiento, total o parcial, formula acusación.

En la etapa intermedia entre la acusación y el juicio oral, el fiscal presenta acusación; descubre los medios de prueba; realiza acuerdos probatorios, se pronuncia sobre impedimentos, nulidades, ofrece los medios de prueba para el juicio, se opone a la admisibilidad del medio de prueba sobreabundante, impertinente, innecesaria o por ser aquellas que contravengan disposiciones del código procesal.

En la etapa de juicio oral, el fiscal sustenta la acusación; realiza el alegato de apertura, interroga a los testigos que ofreció; contrainterroga a los testigos de la defensa; incorpora la evidencia material a través del testigo de acreditación; solicita la reclasificación jurídica del hecho, formula su alegato de clausura. 
En todas las etapas del procedimiento penal, la actuación del fiscal debe regirse entre otros, por los principios que establece el artículo 214 del Código Nacional de Procedimientos Penales. Legalidad, objetividad, eficiencia, profesionalismo, honradez, lealtad y respeto de los derechos humanos reconocidos en la Constitución y Tratados Internacionales (Contreras, 2015).

La importancia del fiscal en el procedimiento acusatorio en México es trascendental y única. Para lo cual se torna necesario de salvaguardar su función y protegerlo de la corrupción, y que su actuar no genere impunidad. De ahí, la importancia de que el juez de enjuiciamiento y control, cuenten con un mecanismo para sustituir la fiscal. Cuando esta función no está realizándose bajo los principios establecidos en legislación.

El mecanismo para lograr la sustitución del fiscal ante su manifiesta y sistemática incapacidad técnica, se encuentra en los principios del sistema acusatorio, y para ello es necesario abordarlos desde una óptica garantista tanto del imputado, como de los derechos de la víctima u ofendido, para lograr un equilibrio entre la acusación y la defensa.

\section{Derecho a la tutela judicial efectiva}

La tutela judicial efectiva es uno de los pilares fundamentales del Estado de Derecho (Cevallos \& Alvarado, 2018), ya que con ella se garantiza los derechos de las víctimas de violaciones de derechos humanos, a través del enjuiciamiento de los responsables y la reparación integral.

La tutela judicial efectiva se encuentra garantizado a nivel constitucional en el artículo 17, reconoce la administración de justicia como un "derecho fundamental de carácter individual que procura la protección de todos los derechos públicos subjetivos" (Araújo-Oñate, 2011, p. 26). La tutela judicial efectiva comprende diversos derechos implica una conjugación de diversos derechos que permiten su misma efectividad. En ese sentido, se reconoce el acceso a la justicia por parte de la víctima, de la cual también se le reconoce al imputado o acusado.

El proceso penal actual es la defensa de los derechos de la víctima del delito y en definitiva su protección, es claro que el ordenamiento jurídico debe responder a esa nueva configuración, estableciendo en las leyes procesales los mecanismos necesarios para otorgar la tutela de los derechos y garantías fundamentales que se reclama. En ese orden, el artículo 24, CE, contiene una serie de vertientes que constituyen el contenido de la tutela judicial efectiva y que confieren una dimensión constitucional a la protección de la víctima.

\section{Principios Procesales del Sistema Acusatorio}

El sistema acusatorio, es un sistema de principios, los cuales se encuentran establecidos en nuestra Constitución y en el Código Procesal de Enjuiciamiento. Los principios para Robert Alexy (1993), son normas que ordenan que algo sea realizado en la mayor medida posible, dentro de las posibilidades jurídicas y fácticas existentes, son mandatos de optimización, que están caracterizados por el hecho de que pueden ser cumplidos o no en diferente grado.

Principios que regulan el sistema sustantivo, procesal y el procedimiento de ejecución de penas, son básicos y obligatorios desde el punto de vista jurídico. 
Entre los principios generales del sistema cobra especial relevancia el que señala, "el esclarecimiento de los hechos es uno de los objetivos del sistema penal acusatorio oral para determinar si se ha cometido un delito, y en todo momento proteger al inocente y procurar que el culpable no quede impune y que los daños causados por el delito se reparen" el cual se encuentra establecido en la fracción I, apartado A, del artículo 20 constitucional. También, en el artículo 2 del código procesal, Dicho principio tiene como finalidad contribuir y asegurar el acceso a la justicia en la aplicación del derecho y resolver el conflicto que surja con motivo de la comisión del delito siempre en un marco de respeto a los derechos humanos y en los tratados internacionales.

El proceso penal en México se rige por diversos principios. El juez debe recurrir al razonamiento moral y jurídico para construir una teoría que describa y prescriba la solución al caso inédito (Arredondo, 2016). Para ello, se abordarán aquellos que son necesarios y útiles para analizar la sustitución del fiscal en las audiencias ante su manifiesta incapacidad técnica. Partiendo de la premisa que la legislación penal busca proteger al inocente y que el culpable no quede impune.

\subsection{Principio de Igualdad ante la ley}

El acceso a la jurisdicción garantiza que todas las personas que intervengan en el procedimiento penal recibirán el mismo trato y tendrán las mismas oportunidades para sostener la acusación o la defensa. Las autoridades velaran por que las personas en las condiciones o circunstancias sean atendidas a fin de garantizar la igualdad sobre la base de equidad en el ejercicio de sus derechos (art. 10 CNPP) El Código Procesal de enjuiciamiento, establece que cuando el Órgano jurisdiccional advierta que existe una manifiesta y sistemática incapacidad técnica del Defensor, prevendrá para que designe otro. Circunstancia, similar debe acontecer en favor de la víctima, la cual la deje en desventaba frente a la incapacidad manifiesta y sistemática del fiscal. (art. $121 \mathrm{CNPP}$ ).

Atendiendo al principio de igualdad ante la ley, el juez de enjuiciamiento o control podrá sustituir al fiscal cuando advierte su manifiesta y sistemática incapacidad, atendiendo a que el culpable no quede impune, principio general del proceso penal acusatorio en México.

\subsection{Principio de Imparcialidad del Juez}

En el sistema acusatorio el juez es miembro de la triada funcional. Garantiza, la imparcialidad, bajo el criterio de ajenidad en relación con el conflicto (Naciones Unidas, 2010). En nuestra Constitución existe una referencia expresa, en el artículo 17, párrafo segundo, en la que señala el derecho de toda persona a acceder a la administración de justicia emitiendo sus resoluciones de manera imparcial.

También, el Código Nacional de Procedimientos Penales, hace referencia que el proceso será sustanciado de manera imparcial y con apego estricto a los derechos humanos previstos en la Constitución, los Tratados y las leyes que de ellos emanen. (art. 12 CNPP)

El juez imparcial no implica que sea una piedra en el proceso acusatorio. Por el contrario, que actúe como garante de los derechos fundamentales, permaneciendo ajeno al litigio que convoca su presencia.

Este principio se nutre de pautas de justicia, equidad, ética, que dan contenido a la actitud que debe observar el juzgador, lo que se traduce en el deber jurídico de no comunicarse ni discutir con una de las artes o su abogado, están ausente la otra. Lo cual está garantizado por la fracción VI, del artículo 
20, Constitucional.

Ante la sustitución del fiscal, el principio de imparcialidad, no se vulnera. Porque el juez únicamente como garante de los derechos humanos, puede válidamente sustituir al fiscal ante esa manifiesta incapacidad técnica. Sin que ello implique la lesión a dicho principio, ya que con ello se procurará un equilibrio, de la cual actualmente tiene ventaja el imputado o acusado, al establecer la garantía de defensa técnica. En contra sentido, será la garantía de una acusación técnica, el cual el juez está obligado garantizar en beneficio de la justicia.

\section{Derecho a la Defensa}

El de defensa es un derecho reconocido a toda persona que es sometida al sistema penal. Este principio constitucional va más allá de la pura y simple condición técnica de que en el proceso penal intervenga el defensor, y de que éste cumpla con su rol de ejercer la defensa técnica. Implica la necesidad de garantizar la intervención sustancial del procesado en el contradictorio, a través de la efectiva presencia en la actividad probatoria; del conocimiento claro y preciso de la imputación; del descubrimiento de los elementos fácticos y jurídicos que son el fundamento de la acusación; de la promoción del proceso mediante el acceso a la jurisdicción, la investigación de parte, la formulación de oposiciones, impugnaciones y conclusiones; de la posibilidad de refutar la argumentación de la parte acusadora, entre otros.

El derecho a la defensa hace parte del núcleo esencial del debido proceso, como quiera que sin él no existiría la condición de legitimidad democrática del proceso penal ni la efectiva realización de la justicia material. Tal condición está claramente desarrollada en el apartado B, fracción VIII, artículo 20 de la Constitución Política de los Estados Unidos Mexicanos, que establece el "derecho a una defensa adecuada por abogado, al cual elegirá libremente incluso desde el momento de su detención”.

También, en el Código Nacional de Procedimientos Penales, tiene su desarrollo, de manera explícita, el derecho de defensa, el cual establece que durante el inicio del procedimiento a comunicarse con su defensor cuando sea detenido, a estar asistido de su defensor al momento de rendir su declaración, tener una defensa adecuada por parte de un licenciado en derecho y el derecho a una defensa técnica, en la cual el órgano jurisdiccional (juez imparcial) al advertir una manifiesta y sistemática incapacidad técnica del defensor podrá ser sustituido. El legislador, garantiza ese derecho de defensa técnica, con la sustitución del defensor. (art. $121 \mathrm{CNPP})$.

\section{Derechos de las victimas u ofendidos}

Constitucional, legal, jurisprudencial se le ha reconocido a la víctima su derecho al esclarecimiento de los hechos, a la justicia y a la reparación. El artículo 20, apartado A, fracción I y apartado B, Constitucional, 109 del Código Nacional de Procedimientos Penales, señalan de forma enunciativa mas no limitativa diversos derechos en favor de la víctima u ofendido.

El derecho al esclarecimiento de los hechos implica que las personas tienen derecho a conocer qué fue lo que realmente sucedió en su caso (Márquez, 2010). El derecho a la justicia conlleva que se haga justicia en el caso concreto, es decir, el derecho a que no haya impunidad y que el culpable sea condenado. El derecho a la reparación integral comporta la adopción de todas las medidas necesarias tendientes a hacer desaparecer los efectos de la conducta punible, y a devolver a la víctima al estado 
en que se encontraba antes de la comisión del hecho dañino (Medellín, 2014).

Así, para materializar ese derecho, es menester garantizar también el derecho a una acusación técnica. Derechos todos que van de la mano con el rol del fiscal a quien, como ya se dijo, compete actuar con diligencia para hacer efectivos los intereses de las víctimas u ofendidos en el proceso penal, de quien se convierte en vocero.

A la víctima u ofendido se le reconoce constitucionalmente su calidad parte dentro del procedimiento penal, pero no basta porque no es un órgano técnico como el fiscal. Quien tiene una funciona como autoridad y parte, por lo tanto, tiene poderes y derechos al igual que la defensa. Entonces, el fiscal debe de ser sustituido cuando ponga en riesgo su objetividad y deje de velar por los intereses de la víctima.

\section{DISCUSIÓN}

La impunidad y corrupción son flagelos presentes en la administración de justicia, principalmente en sede ministerial, en el actuar del fiscal en el desarrollo de las audiencias preliminares y de juicio oral.

El objeto del proceso penal es el esclarecimiento de los hechos, proteger al inocente, procurar que el culpable no quede impune y que el daño causado por el delito se repare. El sistema acusatorio, es un sistema que se rige por principios, estos dotan de fuerza de optimización a la ley. Por lo tanto, elementos del sistema jurídico que tienen validez por su contenido y fuerza argumentativa.

El actuar del fiscal se rige por los principios de legalidad, objetividad, eficiencia, profesionalismo, honradez, lealtad y respeto a los derechos humanos reconocidos en la Constitución y en los Tratados Internacionales.

El derecho fundamental a tutela judicial efectiva es uno de los pilares fundamentales del Estado de Derecho, que en armonía con los principios en el procedimiento garantiza que la administración de justicia. A través de esos derechos y principios, específicamente a la tutela judicial efectiva puede acontecer la sustitución del fiscal y a través del principio de igualdad ante la ley, sin lesionar el principio de imparcialidad del juez, siendo esta la solución a la hipótesis formulada.

Los derechos de defensa y de la víctima u ofendido, con la sustitución del fiscal recibe el mismo trato y tendrán las mismas oportunidades para sostener la acusación o la defensa.

\section{REFERENCIAS}

1. Alexy, Robert. (1993). Teoría de los derechos fundamentales. Madrid, Centro de Estudios Constitucionales.

2. Araujo-Onate, R. M. (2011), Acceso a la justicia y tutela judicial efectiva. Propuesta para fortalecer la justicia administrativa. Visión de derecho comparado. Estudios Socio-Jurídicos, 13(1).

3. Arredondo Bartolo, José María. (2016). Sobre cómo razonamos La Justicia. Derecho global. Estudios sobre derecho y justicia, 2(4), 41-62.

4. Asociación Internacional de Fiscales. (2009). Manual de Derechos Humanos para Fiscales. Los Países Bajos.

5. Baytelman, Andrés \& Duce, Mauricio. (2004). Litigación penal y juicio oral. Centro de estudio de 
justicia de las Américas, Chile.

6. Cámara de Diputados del H. Congreso de la Unión. (1917). Constitución Política de los Estados Unidos Mexicanos

7. http://www.diputados.gob.mx/LeyesBiblio/pdf_mov/Constitucion_Politica.pdf

8. Cámara de Diputados del H. Congreso de la Unión. (2021). Código Nacional de Procedimientos Penales. http://www.diputados.gob.mx/LeyesBiblio/pdf/CNPP_190221.pdf

9. Cevallos Sánchez, Gissela, \& Alvarado Moncada, Zoila. (2018). Tutela judicial efectiva y la relación con el principio de inmediación. Revista Universidad y Sociedad, 10(1), 168-173.

10. Comisión Interinstitucional para la implementación del sistema acusatorio Técnicas del Proceso Oral en el Sistema Acusatorio Colombiano. (2009). Manual General para Operadores Jurídicos. USAID, Colombia Bogotá D.C.

11. Consejo de Europa. (2000). Recomendación Rec (2000)19 a los Estados Miembros sobre la función del Ministerio Fiscal en el Sistema de Justicia Penal. Madrid.

12. Contreras López, Rebeca Elizabeth. (2015). Legalidad y convencionalidad como base del sistema penal acusatorio en México. Cuestiones Constitucionales, (33), 33-51.

13. Fernández, Miguel Ángel (2005). La exclusividad de la función investigadora del Ministerio Público y su vinculación con el quehacer de la Defensoría Penal. Estudios Constitucionales, 3(2),277-307.

14. Márquez Cárdenas, Alvaro E. (2010). Actuaciones de las víctimas como sujetos procesales en el nuevo sistema penal acusatorio. Prolegómenos. Derechos y Valores, XIII (26),11-28.

15. Medellín Urquiaga, Ximena. (2014). Digesto de jurisprudencia latinoamericana sobre derechos de las víctimas. Fundación para el Debido Proceso OAK, Washington.

16. Naciones Unidas. (2010). Acceso a la justicia. Independencia, imparcialidad e integridad de la judicatura. Manual de instrucciones para la evaluación de la justicia penal. Autria.

17. Vasconcelos Méndez, Rubén. (2014). Reforma procesal penal y ministerio público. Serie juicios orales. IIJ-UNAM, México. 